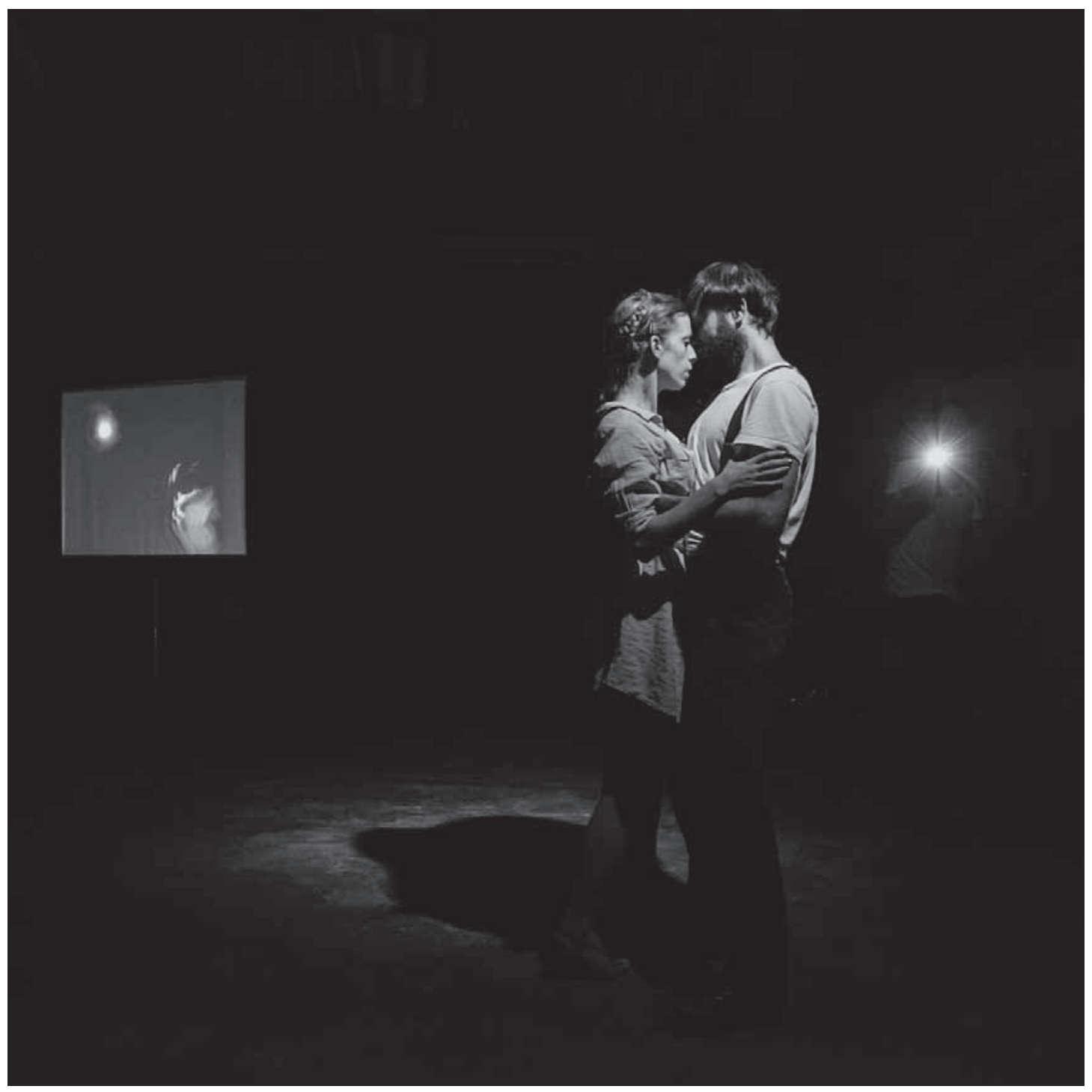


ARS Branca de Oliveira, Heloisa Zani e Amilcar Zani*

ano 12

n. 24

\section{a dobra schumanniana: transitividade e intermeios.}

the schumannian warp: transitivity and intermedium.

palavras-chave:

arte-pesquisa: interdisciplinaridade; multiplicidade; música/vídeo; interatividade.

keywords: art-research; interdisciplinarity; multiplicity; music/video; interactivity.

* Universidade de São Paulo (USP).

Detalhe da fotografia de Carolina Thadeu loriginal a cores) a um ensaio do espectáculo Woyzeck 1978 , criação de Alexandre Pieroni Calado com Alexandra Viveiros e Gustavo Vargas, a partir de Georg Büchner, produzido pela Artes e Engenhos, na Latoaria, Lisboa, em Novembro de 2014. a dobra schumanniana é um concerto-instalação que consiste em performances videográfica e pianística desenvolvidas em ambiente especialmente produzido para tal finalidade. A composição videográfica é projetada simultaneamente tanto nas paredes do ambiente quanto em tela especial, envolvendo completamente um palco central, circular e elevado, onde está localizado um piano. Através de processamento digital em tempo real, as imagens da performance pianística são mescladas à projeção mapeada de um vídeo pré-editado. Este composto videográfico não só busca traduzir a consonância da multiplicidade que atravessa a obra schumanniana com o paradigma estético processual que caracteriza o mundo contemporâneo, como também alia a expressão artística da performance pianística e da videoinstalação à prática da pesquisa organizada e do estudo crítico continuamente renovado, ressaltando a atualidade das proposições arquitetadas pelos gênios da cultura, Robert e Clara Schumann, e Johannes Brahms. Desse modo, o foco de a dobra schumanniana corrobora a coetaneidade de obras poéticas distantes no tempo.

the schumannian warp is a concert-installation consisting of video and piano performances on a specific environment. The video compositions are simultaneously projected on the sidewalls, as well on a special screen, which involves a circular stage where the piano is placed. Through digital processing in real time, the images of the musical performance are merged to a pre-edited video mapped projection. Not only to render the consonance of multiplicities of Schumann's work with the procedural esthetic paradigm that characterizes the contemporary world, this video composite combines the artistic expression of piano and video performances with the practice of organized research and critic studies continuously renewed, enhancing the contemporaneity of propositions created by the culture geniuses Robert and Clara Schumann, and Johannes Brahms. Thereby, the schumannian warp confirms the modernity of poetic works distant in time. 
Escrever sobre uma obra artística significa desencadear uma série de estudos e análises para circunscrever um problema estético no território da reflexão ou teoria. Essa operação, que é investigativa e delimitadora, revela a parte "não artística" da obra, aquilo que a antecipa ou dela devém - dúvidas, bifurcações, passagens, contradições -, multiplicando sentidos e medindo obstáculos que, por outro lado, o espírito movente artístico não se demora em calcular, já que é de sua própria natureza superar. Tendo como ponto de partida o audiovisual a dobra schumanniana (Heloisa e Amilcar Zani e Branca de Oliveira, 2012), o objetivo deste artigo é colocar em relação dois tempos distantes, o da poética e o da reflexão, apresentando os resultados da conexão entre eles. Enquanto o primeiro arrasta para viagens insólitas, interrogando, com seus meios e estilos, sobre paisagens ficcionadas, o segundo excursiona asseguradamente pelos caminhos de um raciocínio demonstrativo, procurando as circunstâncias externamente atestadas em que a obra artística é composta, manifesta-se e cria sentidos. Contudo, a especificidade dessa conexão incita a considerar, com o mesmo grau de severidade, tanto a "ação que faz" - a metodologia -, quanto a "reação ao feito"; atentando, todavia, para o fato de que no plano reflexivo, pode-se apenas traçar conjecturas sobre a heterogeneidade que está no centro subjetivo do processo criativo autoral, mesmo e, sobretudo, se este for coletivo. Encontra-se na obra um pensamento, mas que lhe vem de fora, refeito à imagem de quem o faz. Estende-se a imaginação na direção de sua propriedade dominante, da qual possui-se apenas o germe.

a dobra schumanniana é um concerto-instalação resultante de processos criativos operados em pelo menos dois domínios de conhecimento no campo da arte: música e vídeo. No entanto, é no terreno da "pesquisa da sensação" que o encontro entre eles se agencia, pois é em sua zona de vizinhança, no audiovisual, que o acontecimento estético como ato de criação se realiza. A operação poética audiovisual, por meio de procedimentos técnicos musicais e videográficos, força o pensamento a se experimentar como um ser de sensação. $\mathrm{O}$ modo estético do pensamento é uma ideia ligada à noção de partilha do sensível, isto é, a um sistema de evidências sensíveis que revela, ao mesmo tempo, a existência do comum e dos recortes que nele definem lugares e partes respectivas. $\mathrm{O}$ devir sensível de todo pensamento e o devir pensamento de toda materialidade 
ARS sensível refletem o objetivo do regime estético das artes: a arte como ano 12 transformação do pensamento em experiência sensível da comunidade.

n. 24 O concerto-instalação foi fabulado por um composto de imagens sonoras e visuais que atravessam a história desde o Romantismo. A distância do presente, no regime estético da composição, coloca em cena o passado sem hierarquização de temas ou delimitações fronteiriças entre antigo e moderno, representativo e não representativo, antes, mistura gêneros, suportes e acentua passagens apagando contornos para que, assim, o fluxo e as conexões sejam evidenciados.

As matérias videográficas e musicais possuem algo que lhes é comum, que está como que entranhado em seus meios: é o espaço-tempo. Elas são por isso invocadas a entrar num empreendimento de cooperação que só é possível por haver certo procedimento em música que faz eco naquilo que o vídeo apresenta como procedimento em vídeo - há um assunto, um problema em comum.

No processo criativo de a dobra schumanniana, música e vídeo são convocados para a invenção de um espaço-tempo em que multiplicidades intensivas, instáveis e fragmentárias possam se introduzir, metamorfosear e convergir. Tudo parece se apresentar como séries cuja conexão está potencializada. Pedaços de espaços-tempo aparentemente desconexos são interligados por meio da repetição, sobreposição e justaposição de compostos sonoros e visuais - os quais não param de sobrevir, arrastados por transversalidades que se desprendem dos estratos musicais e videográficos. Desterritorializados, estes compostos tornam-se livres e desenquadrados, quase agregados incompletos ou sobrecarregados, em desequilíbrio permanente. Os motivos e contrapontos flutuantes, interdisciplinares (musicais e videográficos), fazem germinar bifurcações e "linhas de errância", com volteios, nós, velocidades, movimentos, gestos e sonoridades diferentes. São desenvolvidas relações aberrantes, que interpostas e tramadas nas bordas diagonais, irrompem por seus próprios meios para fora das coordenadas verticais e horizontais, harmônicas e melódicas, respectivamente, desencadeando disjunções entre o visual e o sonoro. Estas, por sua vez, desarmam a moldura das percepções ordinárias que enquadra a sensibilidade e, finalmente, libera-a para a potência de afectos e novas formas sensíveis.

No Romantismo alemão o gênio de Schumann arquiteta uma forma que não é desenvolvida senão para as relações, no presente, de velocidade e lentidão pelas quais ela é afetada material e emocionalmente. 
O corpo schumanniano não pára no lugar. [...] O intermezzo [é] consubstancial a toda obra. [...] No limite, só há intermezzi. [...] O corpo schumanniano só conhece bifurcações: ele não se constrói, ele diverge, perpetuamente, ao sabor de uma acumulação de intermédios. ${ }^{1}$

Para além das dicotomias e polaridades está o conceito de trânsito, cuja forma é a mesma da experiência schumanniana de simultaneidade, de disponibilidade e dilatação do presente. Esse estado, que caracteriza a vida contemporânea, parece manter-nos frequentemente em condições de provisoriedade e de indefinições, no qual a estaticidade e o dinamismo da existência tendem paradoxalmente a coincidir. Essencialmente itinerante, o trânsito ou o intermédio, assim como na música, implica um deslizamento para a dimensão espaço-temporal experiência de deslocamento, de transferência, de descentralização. Desse afrouxamento dos laços com o lugar de origem decorre a ausência de um enraizamento. Entretanto, a falta de uma identidade neste caso não é sentida como um vácuo a ser preenchido: ser estrangeiro em sua própria terra e, vice-versa, sentir-se em casa em qualquer lugar. Se por um lado o trânsito, como intermédio, evidencia a movência que prossegue conservando e abolindo simultaneamente as suas determinações precedentes, por outro, rompe os vínculos com o passado e é animado por uma irreprimível vontade de ir além, destacando, nesse duplo movimento, o tempo presente e a presença.

Assim sendo, a dobra schumanniana não faz um trânsito entre o passado e o presente, não comemora um tempo convocando remotas percepções, nem a memória de alguma coisa que possa acrescentar a reminiscência como elemento intensificante do atual; antes, ela conecta partes diferentes de horizontes distantes. Fazendo eco a Nietzsche: Schumann lança uma flecha que, apanhada em pleno voo, é reenviada a outra direção, já sustentada por outras correntes de ar. $\mathrm{O}$ vídeo acrescenta uma percepção não musical da música, soma seus afectos e perceptos ao bloco de sensações musicais compondo, no presente atual, uma obra inteiramente nova, que dá ao acontecimento a substância que o promove. Porém o ato celebrado já não é reinterpretação, releitura, ou tradução, mas sim uma fabulação. Para tanto, foi preciso produzir um material complexo que se encontra tanto na criação das luzes, cores, espaços, volumes, quanto nas composições sonoras.
BRANCA DE OLIVEIRA

HELOISA ZANI

AMILCAR ZANI

a dobra schumanniana:

transitividade e intermeios.

1. DELEUZE, Gilles e GUATTARI, Félix. Mil platôs. Capitalismo e esquizofrenia. Trad. Suely Rolnik. vol. 4. São Paulo: Editora 34, 2007, p. 97. 
2. De origem bergsoniana, esse conceito opera um duplo deslocamento: de um lado, a oposição do um e do múltiplo cessa de ser pertinente; de outro, o problema torna-se o da distinção de dois tipos de multiplicidade latualextensiva, que se divide em partes exteriores umas às outras, como a matéria ou a extensão; e virtual-intensiva, que não se divide senão em dimensões englobadas umas nas outras, como a memória ou a duração). Mais ainda, a antiga oposição aparece em relação com um dos dois tipos - o tipo atual-extensivo, que deriva por "atualização" do tipo virtual-intensivo. Cf. ZOURABICHVILI, François. 0 Vocabulário de Deleuze. Trad. André Telles. Rio de Janeiro: Relume Dumará, 2004, p. 37. .
XXI faz vibrar o conjunto das suas questões, colocando-as no plano da atualidade. E, se os métodos videográficos e musicais são muito diferentes, não somente segundo as especificidades artísticas, mas também segundo cada autor, o problema comum da multiplicidade os reúne. Faz ressoar, um no outro, os modos de expressão. Embora produza sensações de natureza muito diversa, a multiplicidade que opera nos dois planos de expressão cria uma extrema contiguidade entre as sensações não semelhantes produzidas por cada um. Os compostos de sensação, concernentes tanto à música quanto ao vídeo, são enlaçados no distanciamento de uma luz que capta os dois num mesmo reflexo. Quando, por simpatia parcial, as sensações se acoplam, um outro modo do ser surge e vibra.

As ideias vão e voltam, se afastam e se reúnem, tomam formas diversas e, através de uma variação contínua, impulsionam o pensamento a um tipo de devir, de evolução que impede a colocação dos problemas de um modo fixo, fazendo apelo, por meio dessa sucessiva e distinta expressão problemática, a uma espécie de pensamento-ventania. Em a dobra schumanniana, esses problemas propõem a imanência da multiplicidade. Isso coloca o mundo na perspectiva de um conjunto de coisas dobradas umas nas outras - tudo só existe dobrado, dobra de dobra - delírio leibniziano. A matéria é feita de redobras sobre si mesma, as percepções e os sentimentos são dobrados na alma, o mundo inteiro se encontra dobrado. As múltiplas dobras deslocam blocos de espaço-tempo e abrem esses agenciamentos a uma força cósmica. As dobras luminosas e sonoras fazem o vídeo e a música transpor limiares de especificidade ora por relações de afrontamento, ora de complementaridade, ora de separação, ora de troca. Mas esse movimento coloca ambos num mesmo plano de consistência, de composição, de imanência.

\section{A obra}

a dobra schumanniana é uma obra de caráter multimidiático e interativo que alia linguagem eletrônica e música erudita por meio de performances pianística e videográfica. Enquanto a performance videográfica se abre, com multiprojeções no espaço, o duo de pianistas interpreta, ao piano, o Quinteto para piano op. 44 em Mi bemol maior 
(1842), de Robert Schumann, arranjo de Clara Schumann para piano a quatro mãos, e o Quarteto de cordas op. $51 n^{\circ} 1$ em Dó menor (1873), de Johannes Brahms, com arranjo do próprio compositor para piano a quatro mãos.

Esse tipo de arranjo para piano a quatro mãos de obras musicais dos mais variados gêneros foi amplamente utilizado no século XIX como meio de divulgação de obras que requeriam vários músicos para sua execução. Muitos deles, devido à grande experiência musical de quem os realizou, puderam se afirmar como verdadeiras obras originais para piano, uma vez que se tornaram mais do que simples acomodações ao instrumento das notas de uma obra musical escrita para conjuntos de formação específica. Transformaram-se em traduções de um meio de realização musical para outro, como podem comprovar as obras escolhidas para compor este concerto-instalação que tem em Robert Schumann seu eixo central.

O espaço onde o concerto-instalação acontece, em formato de arena, é composto por um palco central, redondo e elevado, em cujo centro está o piano para a performance dos músicos. Envolve o palco uma tela especial, transparente e circular, em que são realizados experimentos em live image, projeções que mesclam imagens da própria performance pianística a vídeos previamente editados, através de processamento digital em tempo real. O vídeo, por sua vez, contempla a atmosfera schumanniana pelas filmagens captadas na Alemanha (2011), em locais onde está conservada e mantida a maior parte dos registros documentais da vida e obra de Robert e Clara Schumann.

A coordenação das múltiplas projeções simultâneas sobre a tela em 360 graus que circunda o palco e as paredes internas que circunscrevem todo o espaço da apresentação é realizada em videomapping, como num jogo vivo de reflexões em que som e imagem se rebatem e se multiplicam em inúmeras camadas. Consonante com o paradigma estético processual que vem caracterizando a produção artística contemporânea - e de espírito predominantemente trágico -, a organização espaço-temporal das diversas categorias de imagens audiovisuais tem como eixo a reverberação do conceito de "multiplicidade", criado por Bergson, trabalhado por Deleuze e que atravessa a obra schumanniana.

A seguir, apresenta-se uma sequência ilustrativa do projeto arquitetônico para montagem em espaço retangular (figuras 1, 2 e 3). 


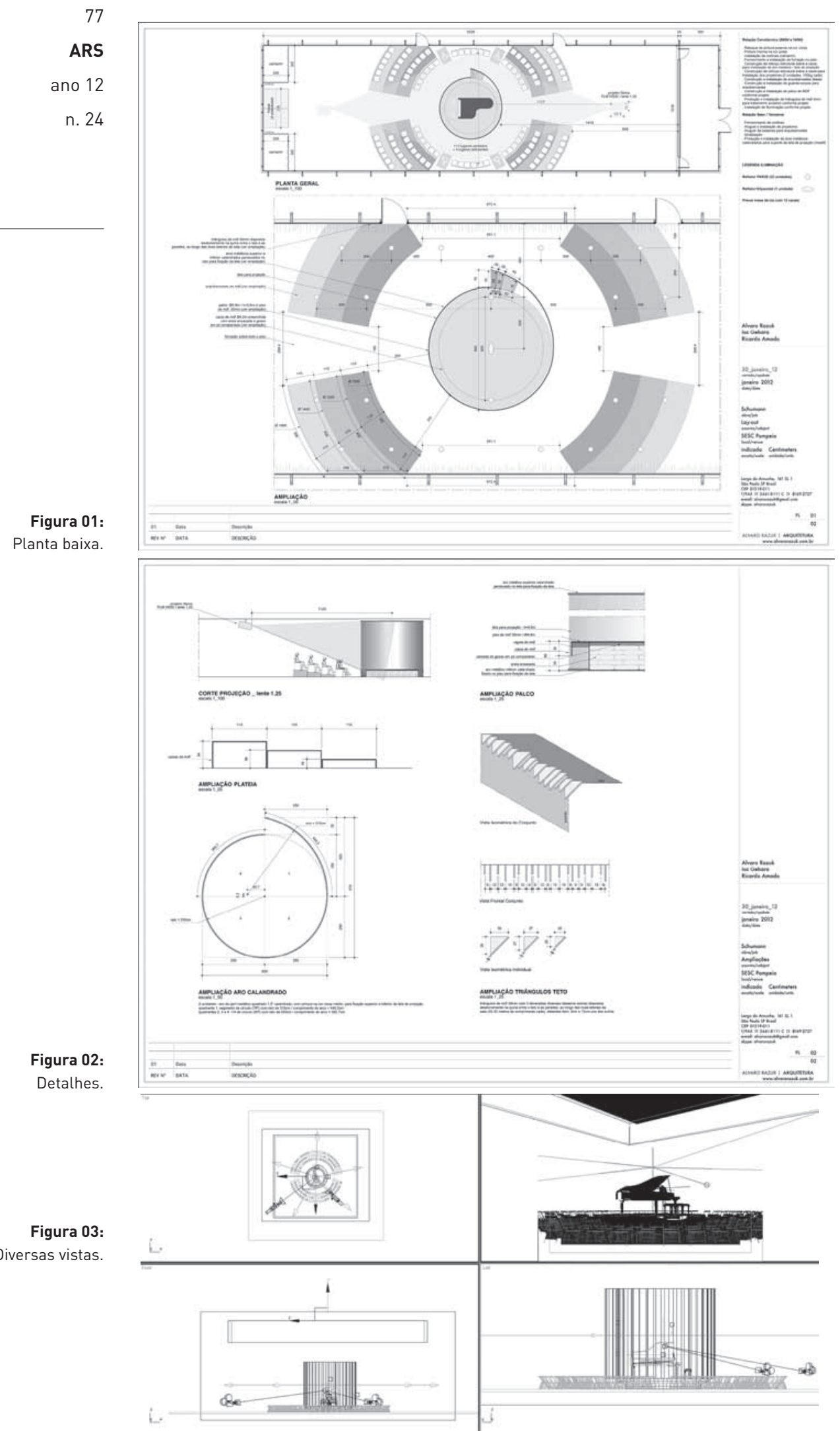




\section{Registro fotográfico da estreia de a dobra schumanniana}

Na sequência, apresenta-se o registro parcial de imagens captadas durante o concerto-instalação. As imagens foram realizadas com várias câmeras posicionadas em diferentes ângulos de visão (figuras 4, 5 e 6).

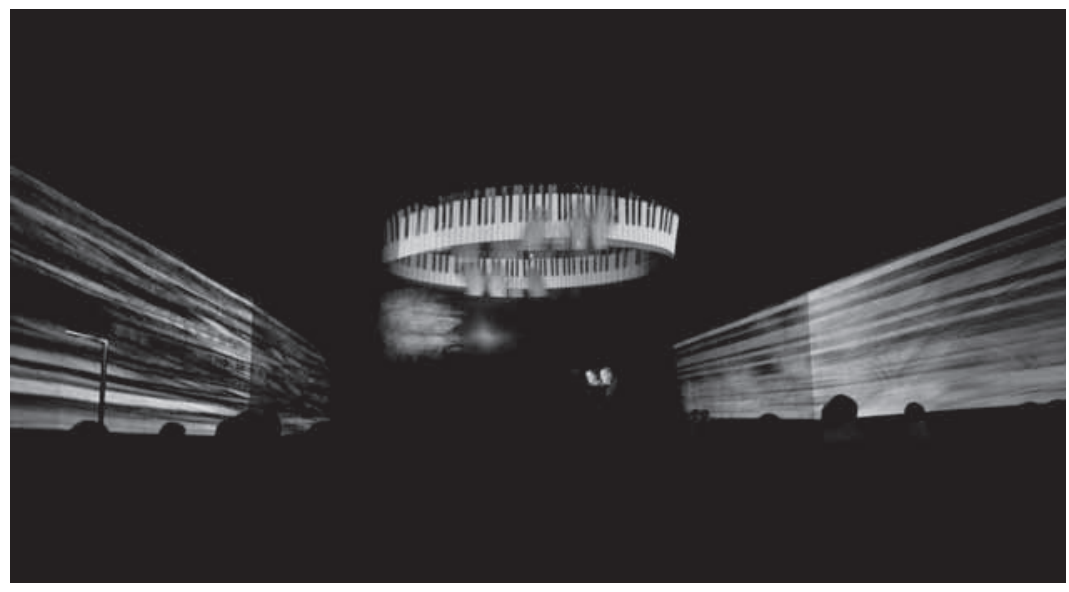

\section{Porque Schumann}

Novos aspectos e reflexões a respeito de Robert Schumann vêm ganhando notoriedade. Estudos acerca da atualidade de sua obra vêm sendo ininterruptamente salientados. A dedicação simultânea de Schumann tanto à música quanto à literatura singularizou sua criação pianística e tornou fabulosa a conexão entre o processo de criação e sua produção crítico-literária. Isso fez com que ele inaugurasse, à sua época, novas formas em música - as expressões musicais românticas. Robert Schumann espelha a característica do múltiplo, conceito introduzido pela literatura e filosofia do movimento romântico alemão, trazendo para a música, através de um processo objetivo de estudo e de criação poética, a essência daquele movimento.

O Romantismo é uma revolução, uma revolução total. Subverteu ao mesmo tempo a sensibilidade e a ética de um período, suas formas de arte, seu pensamento literário, filosófico e religioso; para aqueles que então se consagraram, significou uma conversão. ${ }^{3}$
Figura 4:

Vista frontal anterior de a dobra schumanniana. Fotografia: João Caldas.

3. BOUCOURECHLIEV, André. Schumann. Paris: Seuil, 1956, p. 9. 
O pluralismo e a contradição, inerentes à multiplicidade que caracteriza o contexto artístico de hoje, sempre fizeram parte do procedi-

ก. 24

4. Cf. ZANI NETTO, Amilcar. Schumann e seus duplos: uma leitura da Sonata op. 11 em fá sustenido menor. Cadernos de Estudo: Análise musical.

São Paulo: Atravez, n. 2 , 1990, p. 31-44.

Figura 5:

Vista aproximada lateral esquerda de a dobra schumanniana.

Fotografia: João Caldas.

Figura 6:

Vista lateral direita 1 de a dobra schumanniana Fotografia: João Caldas

mento schumanniano. A coexistência de múltiplas tendências em sua personalidade, que nunca deixaram de se sobrepor, trazem implicações consideráveis, principalmente sobre questões de interdisciplinaridade que caracterizam a produção estética contemporânea. Esse significativo conflito, ao mesmo tempo em que manifesta positivamente sua força criativa e o mantém em um equilíbrio extremamente precário diante da sucessão dos acontecimentos de sua vida, tornou possível a convivência entre a realidade e a fantasia, a vida e a morte, a afetividade e o rancor, a sanidade e a loucura, marcando, distintivamente, sua potência e atualidade. $^{4}$

Clara Wieck, mais tarde Clara Schumann, pode ser considerada, ao lado de Franz Liszt, a maior pianista do século XIX. Ela foi a fonte inspiradora da obra de Robert Schumann e sua grande paixão. Johannes Brahms, ao procurar Schumann com a finalidade específica de tornar-se seu aluno, transforma-se no terceiro elemento da configuração de um triângulo afetivo que estabelece os desígnios e o caminho percorrido pela música naquele século.

O estudo, enquanto processo de aquisição, ampliação e produção do conhecimento é considerado por Schumann a única via de acesso à criação de qualquer obra consistente. Isso confere ao crítico e compositor um papel capaz de inflectir o curso da história da música. A historiografia musical do movimento romântico alemão, e toda a produção de música subsequente, até os nossos dias, não teria sido viável sem o vigor da obra schumanniana.
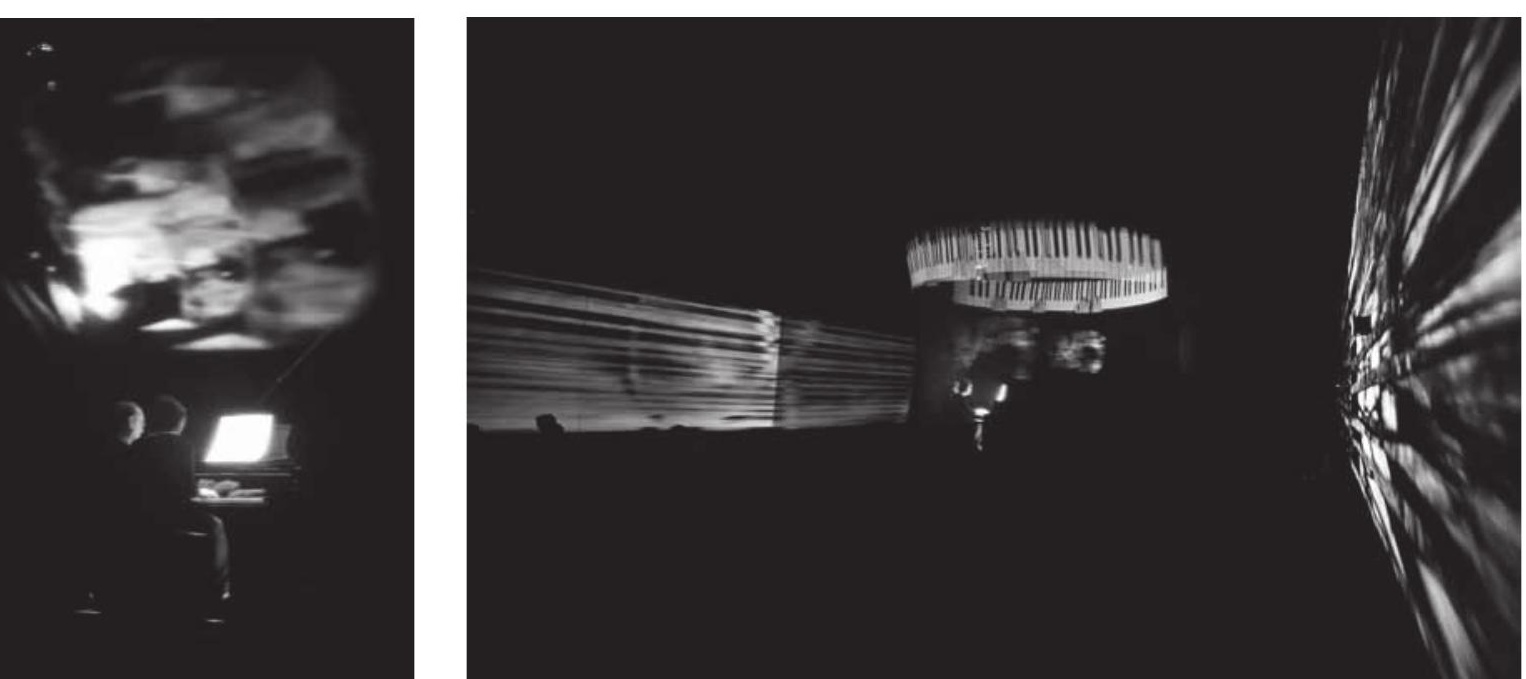


\section{Bibliografia complementar}

PERNIOLA, Mario. Pensando o ritual. Sexualidade, morte, mundo.

São Paulo: Studio Nobel, 2000.

VALÉRY, Paul. Variedades. São Paulo: Iluminuras, 1999.

Prof. Dr. Amilcar Zani é professor titular nos cursos de graduação e pós-graduação do Departamento de Música da Escola de Comunicações e Artes da Universidade de São Paulo (ECA-USP). Pianista e pesquisador, é também arquiteto. Sua especialização inclui estudos de piano em Portugal, Alemanha e Estados Unidos. Os projetos de pesquisa que coordena enfatizam o Romantismo Germânico de Robert Schumann e a Segunda Escola de Viena na Coleção Clara e Edward Steuermann.

Profa. Dra. Heloisa Zani é docente do Departamento de Música da Escola de Comunicações e Artes da Universidade de São Paulo (ECA-USP) nos cursos de graduação e pós-graduação, tem a busca de novas propostas didáticas em relação ao ensino do piano uma constante em suas atividades. Em seus estudos abordou a produção musical de Hans Eisler e também a correspondência entre Clara e Edward Steuermann e René Leibowitz. 0 interesse pela música de câmara levou-a ao estudo minucioso da produção musical para piano a quatro mãos e dois pianos.

Profa. Dra. Branca de Oliveira é artista, pesquisadora e docente nos programas de graduação e pós-graduação do Departamento de Artes Plásticas da Universidade de São Paulo (ECA-USP). Fundadora e coordenadora, desde 2003, do grupo de pesquisa “Poética da Multiplicidade: modos contemporâneos de produção de imagens poéticas”, consolidado e certificado pelas instituições USP e CNPq. Com procedimentos criativos derivados de potencialidades gráficas da infraestrutura operacional tecnológica, da combinatória do algoritmo e da lógica de processamento de dados, realiza experimentos estéticos em cujo horizonte está o problema da constituição de um "corpo intensivo".
BRANCA DE OLIVEIRA

HELOISA ZANI

AMILCAR ZANI

a dobra schumanniana:

transitividade e intermeios.
Detalhe da fotografia de João Caldas da projeção de vídeo do concerto-instalação a dobra schumanniana de Heloisa e Amilcar Zani e Branca de Oliveira, 2012.

Artigo recebido em 30 de outubro de 2014 e aprovado em 13 de novembro de 2014 


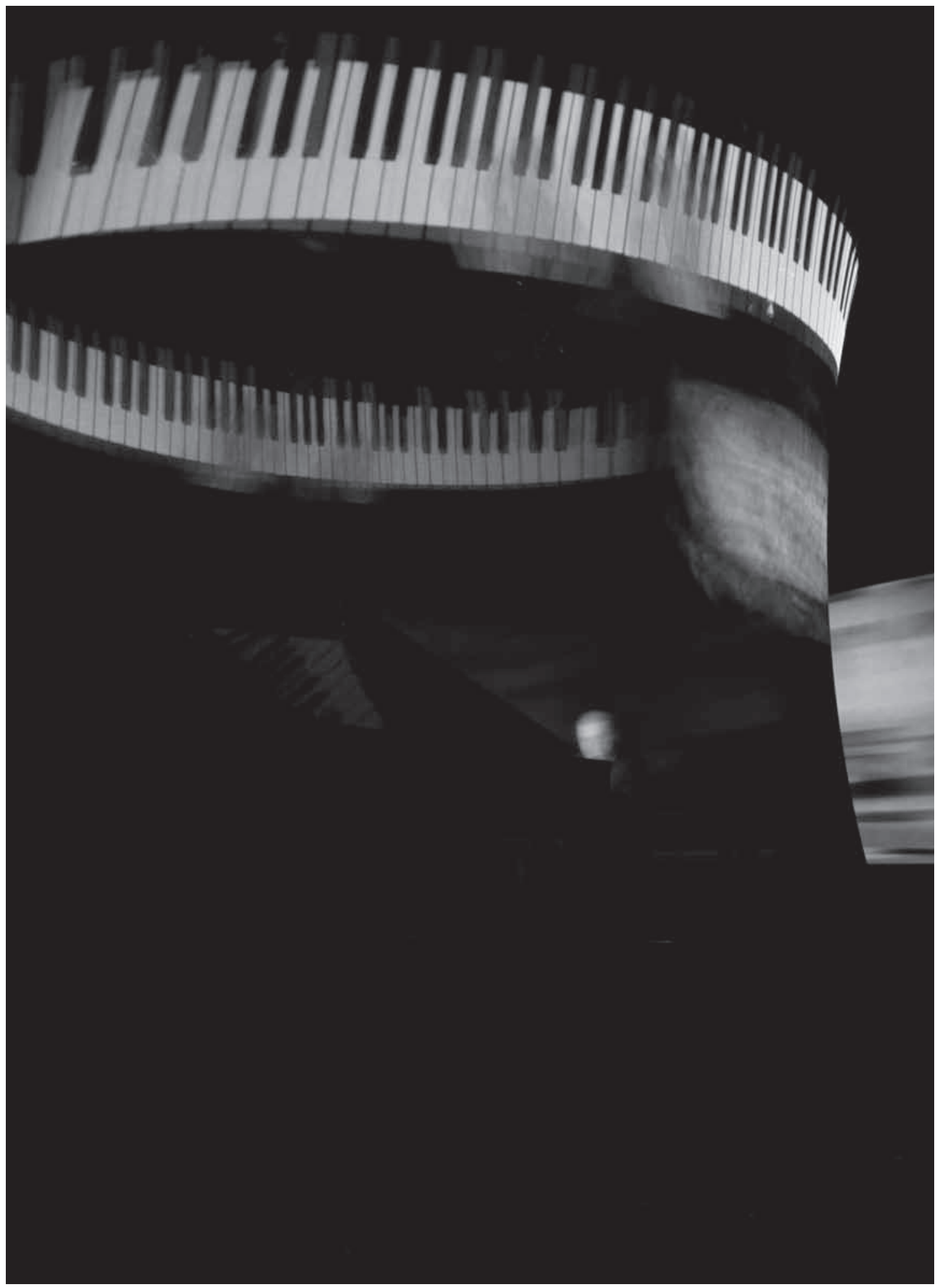

